\title{
A Justiciabilidade do Direito à Saúde, Previsto no Pacto Internacional Sobre Direitos Econômicos, Sociais e Culturais, a Partir de Sua Dimensão de Proteção Ambiental
}

\author{
THE JUSTICIABILITY OF THE RIGHT TO HEALTH IN THE INTERNATIONAL \\ COVENANT ON ECONOMIC, SOCIALAND CULTURAL RIGHTS (ICESCR) \\ THROUGH ITS DIMENSION OF ENVIRONMENTAL PROTECTION
}

Marco Túlio Reis Magalhães ${ }^{(*)}$

\section{RESUMO}

Este artigo examina uma importante discussão jurídica sobre a justiciabilidade do direito à saúde, previsto no Pacto Internacional sobre Direitos Econômicos, Sociais e Culturais, a partir do estudo de sua dimensão de proteção ambiental, a qual foi afirmada expressamente no art. 12.2 (b), considerando também que a Constituição Federal brasileira oferece expressa proteção à saúde. O presente trabalho enfatiza o debate sobre as implicações dos limites e possibilidades de se considerar o direito à saúde implementado a partir de sua dimensão de proteção ambiental. Partindo do exame dos artigos do Pacto Internacional, pode-se apontar que, em primeiro lugar, o Pacto Internacional e a Constituição Brasileira consideram o direito à saúde um direito humano fundamental. Em segundo lugar, o Pacto Internacional determina que o grau de implementação desse direito é variável nos diversos países, o que não exclui a adoção obrigatória de um mínimo de medidas necessárias e, em terceiro, o direito à saúde é também implementado por uma dimensão de proteção ambiental, enquanto um importante fator que contribui para a sua justiciabilidade.

(*) Mestrando em Direito pela Universidade de Brasília (UnB); Procurador Federal em Brasília/DF. E-mail: <marucosam @yahoo.com.br>. Recebido em 15.8.07. Aprovado em 30.4.08. 


\section{Palavras-chave}

Constituição Federal Brasileira; Justiciabilidade do Direito à Saúde; Meio Ambiente; Pacto Internacional sobre Direitos Econômicos, Sociais e Culturais.

\section{ABSTRACT}

This article provides a review of an important discussion about the justiciability of the right to health, stated in the International Covenant on Economic, Social and Cultural Rights (ICESCR), starting with the study of its environmental protection dimension, which was expressively stated in article 12.2(b). Moreover, it is known that Brazilian Constitucion affords explicit protection to Health. This work will focus on the debate about the implications of the limits and possibilities to consider the right to health implemented through its environmental protection dimension. From a survey of the articles of the Internacional Covenant, some important lessons can be drawn: first, the Internacional Covenant and the Brazilian Constitucion consider the right to health as a fundamental human right; second, the Internacional Covenant determines that the level of implementation of the right to health depends on the specific conditions of each country, which does not mean that it is not obligatory the adoption of a minimum level of necessary healthy measures; third, the right to health is also implement through a dimension of environmental protection, which is an important element that contributes for the justiciability of this right.

\section{Keywords}

Brazilian Constitucion; Environment; International Covenant on Economic, Social and Cultural Rights; Justiciability of the Right to Health.

\section{INTRODUÇÃO}

Busca-se aqui analisar alguns aspectos que influem na justiciabilidade ${ }^{(1)}$ do direito à saúde, partindo de sua delimitação pelo Pacto Internacional

(1) O termo justiciabilidade usado aqui (justiciability) diz respeito à idéia de aplicabilidade dos direitos, ou seja, à possibilidade de fazer valer os direitos econômicos, sociais e culturais, quando não previamente garantidos pelo Estado. Nesse sentido: SCHEININ, Martin. Economic and social 
sobre Direitos Econômicos, Sociais e Culturais. Em especial, de que forma sua implementação se envolve com a temática de proteção do meio ambiente ${ }^{(2)}$, a partir do art. 12.2 (b) do referido Pacto.

Busca-se definir a observância do direito à saúde no ordenamento jurídico brasileiro, bem como sua vinculação ao referido Pacto. Em seguida, de forma geral, busca-se delimitar os limites e possibilidades de implementação do direito à saúde, a partir das prescrições do Pacto e dos comentários gerais da Organização das Nações Unidas.

Pergunta-se como e se essa prescrição normativa pode reforçar a proteção ambiental e vice-versa. A esses questionamentos, soma-se o seguinte: em que medida essa prescrição do Pacto envolve deveres dos Estados obrigados e, em que medida ocorre o monitoramento do cumprimento de tais deveres.

\section{ANÁLISE DO PACTO INTERNACIONAL SOBRE DIREITOS ECONÔMICOS, SOCIAIS E CULTURAIS E DAS DISPOSIÇÕES CONSTITUCIONAIS BRASILEIRAS A RESPEITO DO DIREITO À SAÚDE}

\section{Sobre o Pacto e o direcionamento geral do direito à saúde na Constituição Federal}

O Pacto Internacional sobre Direitos Econômicos, Sociais e Culturais foi adotado pela XXI Sessão da Assembléia-Geral das Nações Unidas, em 19 de dezembro de 1966. O Brasil tornou-se membro signatário do documento, tendo o Congresso Nacional brasileiro aprovado seu texto por meio do Decreto Legislativo n. 226(1), de 12 de janeiro de 1991 (e Decreto Presidencial n. 591, de 6 de julho de 1992), depositado a carta de adesão ao Pacto em 24 de janeiro de 1992, tendo o referido Pacto entrado em vigor no Brasil em 24 de abril de 1992.

rights as legal rights. In: ASBJOM, Eide; KRAUSE, Catarina; ALLAN, Rosas (Eds.). Economic, social and cultural rights: a textbook. 2nd ed. Dordrecht: Martinus Nijhoff Publishers, 2001. p. 29-30. O termo justicialização também pode ser encontrado na doutrina. Nesse sentido: BEDÊ, Fayga Silveira. A erosão normativa da Constituição e os seus reflexos sobre a justicialização dos direitos fundamentais sociais. In: LIMA, Martonio Mont'Alverne Barreto; ALBUQUERQUE, Paulo Antonio Menezes (Orgs.). Democracia, direito e política: estudos internacionais em homenagem a Friedrich Müller. 1. ed. Florianópolis: Conceito Editorial; Fundação Boiteux, 2006, v. 1. p. 225-235.

(2) No Brasil, a questão ambiental é relevante, não só por sua biodiversidade, mas por alcançar proteção constitucional. A proteção ambiental, difusa em diversos artigos da Constituição de 1988, recebe capítulo próprio, expresso no art. 225. O art. 170 destaca como princípio geral da atividade econômica a defesa do meio ambiente, exigindo tratamento diferenciado das atividades causadoras de impacto ambiental. Os arts. 23 e 24 informam a repartição de competência administrativa e legislativa entre os entes federados quanto à questão do meio ambiente. 
Neste trabalho, importa analisar alguns artigos do diploma internacional. Antes disso, é interessante notar que o Decreto n. 591 - de 6 de julho de 1992 - dispõe que o Pacto será executado e cumprido tão inteiramente como nele se contém. Portanto, um primeiro importante aspecto a ser considerado, em relação a todo e qualquer direito disposto no documento (inclusive o direito à saúde), é a determinação jurídica da necessidade de seu fiel e integral cumprimento, sem a possibilidade de adoção de exceções que não estejam previstas nele.

Cumpre ressaltar ainda sobre como a Constituição Federal brasileira de 1988 dispõe acerca do direito à saúde ${ }^{(3)}$. Dentro do título da Ordem Social, o direito à saúde está albergado, de forma concentrada, no art. 196; as definições de ações prioritárias, da organização do sistema de saúde e outros aspectos, estão enumerados nos arts. 197 a 200, bem como nos arts. 23 e 24 (quanto às delimitações de competências administrativa e legislativa). Nesse sentido, destaca-se o art. 196:

Art. 196. A saúde é direito de todos e dever do Estado, garantido mediante políticas sociais e econômicas que visem à redução do risco de doença e de outros agravos e ao acesso universal e igualitário às ações e serviços para sua promoção, proteção e recuperação.(4)

Segundo José Afonso da Silva, a saúde é concebida como direito de todos e dever do Estado, "que a deve garantir mediante políticas sociais e econômicas que visem à redução do risco de doença e de outros agravos"(5). Portanto, o ordenamento jurídico brasileiro alberga em sua Constituição Federal a preocupação com o direito à saúde, que se configura num direito com múltiplas perspectivas, ou seja, direito de todos os cidadãos e dever do Estado, no sentido de prover meios e recursos de acesso e promoção da saúde ${ }^{(6)}$.

(3) Segundo Flávia Piovesan: "Quanto à indivisibilidade dos direitos humanos, há que se enfatizar que a Carta de 1988 é a primeira Constituição que integra ao elenco dos direitos fundamentais, os direitos sociais e econômicos, que nas Cartas anteriores restavam pulverizados no capítulo pertinente à ordem econômica e social (...)." PIOVESAN, Flávia. Justiciabilidade dos direitos sociais e econômicos no Brasil: desafios e perspectivas. In: LIMA, Martonio Mont'Alverne Barreto; ALBUQUERQUE, Paulo Antonio Menezes (Orgs.), op. cit., v. 1, p. 253-254.

(4) BRASIL. Constituição (1998). Constituição da República Federativa do Brasil. Disponível em: <http://www.planalto.gov.br/ccivil_03/Constituicao/Constituiçao.htm>. Acesso em: 25 jul. 2007.

(5) SILVA, José Afonso da. Curso de direito constitucional positivo. 23. ed. São Paulo: Malheiros Ed., 2004. p. 811.

(6) "A ordem constitucional de 1988 acabou por alargar as tarefas do Estado, incorporando fins econômico-sociais positivamente vinculantes das instâncias de regulação jurídica. A política deixa de ser concebida como um domínio juridicamente livre e constitucionalmente desvinculado. Os domínios da política passam a sofrer limites, mas também imposições, por meio de um projeto material vinculativo. Surge verdadeira configuração normativa da atividade política." PIOVESAN, Flávia, op. cit., p. 254. 


\section{Sobre os artigos gerais e introdutórios do Pacto Internacional sobre Direitos Econômicos, Sociais e Culturais}

Tendo em vista a forma como o Estado brasileiro adotou o Pacto, passa-se à análise das suas disposições gerais essenciais ao estudo aqui almejado. $\mathrm{O}$ art. $1^{\circ} .2$ já apresenta importante característica para a conformação do direito à saúde, senão vejamos:

\section{PARTE I}

ART. 1으

(...)

2. Para a consecução de seus objetivos, todos os povos podem dispor livremente de suas riquezas e de seus recursos naturais, sem prejuízo das obrigações decorrentes da cooperação econômica internacional, baseada no princípio do proveito mútuo, e do Direito internacional. Em caso algum, poderá um povo ser privado de seus próprios meios de subsistência. ${ }^{(7)}$

Portanto, para a implementação e garantia do direito à saúde, um primeiro aspecto a ser analisado é a possibilidade de os povos disporem livremente sobre seus recursos, a fim de atender, em maior grau possível, às demandas relacionadas a este direito. Ao mesmo tempo, este expediente implica a análise da sustentabilidade ambienta/(8) de tal intento, haja vista que esta disposição livre das riquezas não pode fazer ruir a dimensão ambiental que o direito à saúde agrega.

Em relação aos deveres dos Estados para implementação do Pacto, cumpre ressaltar o que dispõe o seu art. $2^{\circ}$ :

\section{PARTE II}

ART. $2^{\circ}$

1. Cada Estado Parte do presente Pacto compromete-se a adotar medidas, tanto por esforço próprio como pela assistência e cooperação

(7) DECRETO Presidencial n. 591, de 6.7.92. Disponível em: <http://www.planalto.gov.br/ccivil_03/ decreto/1990-1994/D0591.htm>. Acesso em: 25 jul. 2007.

(8) "Given the clear evidence that economic growth has not halted poverty in the Third World, nor has it stopped environmental degradation and contamination in the First World, nations are in a process of reconsidering the relationship between economy and ecology. Thus, to the traditional position of economic growth at all costs, it followed a more integral idea of development that not only responds to the economic aspect but also considers other elements, such as the human dimension of the economy as well as environmental dimensions. The paradigm of this conception is the idea of sustainable development: "In this context it is considered that sustainable development pursues the achievement of three objectives: a purely economic objective, efficiency in the use of resources, and quantitative growth; a social and cultural objective, the restraints of poverty, the conservation of social and cultural systems, and social equity; and an ecologic objective, the preservation of physical and biological systems (natural resources lato sensu) that support the life of human beings." [17]" PICOLOTTI; Romina; BORDENAVE; Sofía. A new development strategy for the americas: a human rights and the environment perspective. Disponível em: <http://www.cedha.org.ar/ docs/doc79-eng.htm>. Acesso em: 14 jan. 2006. 
internacionais, principalmente nos planos econômico e técnico, até o máximo de seus recursos disponíveis, que visem a assegurar, progressivamente, por todos os meios apropriados, o pleno exercício dos direitos reconhecidos no presente Pacto, incluindo, em particular, a adoção de medidas legislativas. ${ }^{(9)}$

Este artigo é importante para o estudo da justiciabilidade do direito à saúde previsto no Pacto, pois indica, de certa forma, o grau de intensidade de implementação dos direitos nele previstos. Isto é, os Estados estão comprometidos a adotar medidas, ou seja, não podem ficar inertes. Entretanto, a redação do artigo deixa claro que a implementação desses direitos deve ser realizada progressivamente, em razão das condições técnicas e econômicas de cada país, bem como pela atuação legislativa, na conformação de regras jurídicas, que permita o seu cumprimento.

O art. 3 , por seu turno, determina que não deverá existir qualquer discriminação entre homens e mulheres, no que diz respeito à implementação dos direitos nele previstos. O art. 4ำ esclarece como o Pacto orienta a implementação dos direitos nele previstos e, conseqüentemente, aponta o caminho para a justiciabilidade do direito à saúde:

\section{PARTE II}

ART. $4^{\circ}$

Os Estados Partes do presente Pacto reconhecem que, no exercício dos direitos assegurados em conformidade com presente Pacto pelo Estado, este poderá submeter tais direitos unicamente às limitações estabelecidas em lei, somente na medida compatível com a natureza desses direitos e exclusivamente com o objetivo de favorecer o bem-estar geral em uma sociedade democrática. ${ }^{(10)}$

Este artigo é de fundamental importância, pois define como e em que extensão será possível a limitação das disposições contidas no Pacto, ou seja, (1) somente por meio de atividade legislativa; e (2) desde que compatível com a natureza do direito em análise; e (3) com o escopo de, com tal medida, favorecer o bem-estar geral dos cidadãos. Portanto, qualquer medida restritiva que não atenda a esses requisitos estará violando as suas prescrições.

Os artigos analisados foram transcritos e comentados, pois são de aplicação geral a todos os direitos previstos no Pacto. Eles funcionam como uma

(9) DECRETO Presidencial n. 591, de 6.7.92, cit.

(10) Id. Ibid. 
baliza de interpretação e segurança do seu cumprimento e implicam em parâmetros extras para a justiciabilidade dos direitos nele previstos.

\section{0 art. 12 e a apreensão do conteúdo normativo do direito à saúde a partir de seu preceito normativo e dos comentários gerais da ONU (General Comment n. 14 [2000])}

Eis o que dispõe o art. 12 do Pacto Internacional:

ART. 12

1. Os Estados-Partes do presente Pacto reconhecem o direito de toda pessoa de desfrutar o mais elevado nível possível de saúde física e mental.

2. As medidas que os Estados-Partes do presente Pacto deverão adotar com o fim de assegurar o pleno exercício desse direito incluirão as medidas que se façam necessárias para assegurar:

a) a diminuição da mortinatalidade e da mortalidade infantil, bem como o desenvolvimento é das crianças;

b) a melhoria de todos os aspectos de higiene do trabalho e do meio ambiente;

c) a prevenção e o tratamento das doenças epidêmicas, endêmicas, profissionais e outras, bem como a luta contra essas doenças;

d) a criação de condições que assegurem a todos assistência médica e serviços médicos em caso de enfermidade. ${ }^{(11)}$

O artigo dispõe que toda pessoa tem o direito de desfrutar de saúde física e mental, ou seja, a saúde em seus diversos aspectos. O ponto mais importante para análise da justiciabilidade do direito à saúde se refere à expressão "o mais elevado nível possível"(12). Tal expressão denota, em consonância com as disposições contidas nos artigos iniciais (gerais) do Pacto, a idéia de que o direito à saúde não será implementado de forma

(11) Id. Ibid.

(12) "O conceito de nível mais elevado possível de saúde (The notion of "the highest attainable standard of health) do art. 12.1 leva em conta pré-condições biológicas e socioeconômicas e os recursos estatais disponíveis. Há inúmeros aspectos não referidos unicamente à relação entre Estados e indivíduos; particularmente, boa saúde não pode ser provida inteiramente pelo Estado, nem proteção contra toda e qualquer possível causa de debilidade da saúde humana. Assim, fatores genéticos, susceptibilidade individual a doenças ou adoção de estilos de vida não saudáveis ou de risco podem desempenhar papel central para a saúde do indivíduo. Conseqüentemente, o direito à saúde deve ser entendido como um direito à fruição de uma variedade de acessos, bens, serviços e condições necessárias à realização do nível mais elevado possível de saúde." [tradução livre]." U. N. CESCR, General Comment 14, U.N. Doc. E/C. 12/200/4 (2000). Disponível em: <http://www.unhchr.ch/tbs/doc.nsf/(symbol)/E.C.12.2000.4.En?OpenDocument>. Acesso em: 14 jan. 2007. 
idêntica nos diversos países ${ }^{(13)}$, mas conforme determinadas variáveis, embora se mantenha o compromisso estatal de implementá-lo da maneira mais elevada possível. Em suma, a implementação de tal direito depende de fatores socioeconômicos de cada Estado-Parte ${ }^{(14)}$.

Contudo, conforme se apreende do art. 12.2, a necessidade de condicionamento a determinadas variáveis não obsta o dever estatal de implementação da forma mais plena possível ${ }^{(15)}$. Tanto que o Pacto prevê a estipulação de determinadas diretrizes que devem ser asseguradas por medidas a serem adotadas pelos Estados-Partes. Tais diretrizes estão nas alíneas "a" a "d" do referido art. 12.2.

E a intersecção de análise do direito à saúde com uma dimensão de proteção ambiental se encontra no art. 12.2 (b), com a imposição de medidas de todas as melhorias possíveis relacionadas ao meio ambiente.

Quanto ao conteúdo normativo do artigo em análise, os comentários gerais do Comitê da ONU ressaltam que, enquanto o art. 12.1 traz a definição do direito à saúde, as diretrizes (obrigações ou medidas impostas) enumeradas no art. 12.2 não são exaustivas, ou seja, não são numerus clausus. Assim, a implementação do direito à saúde pode se valer de outras medidas e diretrizes a serem estipuladas e cumpridas pelos Estados-Partes.

Segundo os comentários gerais da ONU, o direito à saúde deve ser entendido em uma perspectiva mais ampla e multifacetária, pois tal direito contém

(13) Nesse sentido, o comentário geral n. 14 destaca que o "Comitê da ONU está ciente de que para milhões de pessoas ao redor do mundo a plena fruição do direito à saúde ainda é um objetivo distante. Além disso, em muitos casos, especialmente aos que vivem em níveis considerados de pobreza, este objetivo está se tornando crescentemente remoto. O Comitê da ONU reconhece os enormes obstáculos estruturais e de outra natureza, resultantes de fatores internacionais e outros diversos que estão além do controle dos Estados partes, a impedir a plena realização do art. 12 pelos diversos Estados partes." [tradução livre] U. N. CESCR, General Comment 14, U. N. Doc. E/ C. $12 / 200 / 4$ (2000), cit.

(14) Nesse sentido, o comentário geral n. 14 ressalta que "o esboço histórico e que o preceito normativo do art. 12.2 permitem apreender que o direito à saúde abarca um amplo espectro de fatores socioeconômicos que promovem condições nas quais as pessoas podem usufruir de uma vida saudável, e direciona a certos determinantes de saúde, como existência de comida a permitir adequada nutrição, moradia, acesso à água potável e segura e adequação sanitária, condições de trabalho seguras e adequadas e um meio ambiente sadio e equilibrado [tradução livre]". U. N. CESCR, General Comment 14, U. N. Doc. E/C. 12/200/4 (2000), cit.

(15) A esse respeito, interessante destacar o entendimento de Flávio Pansieri, que destaca argumento em crescente aceitação na comunidade jurídica, mas, sujeito ainda a muitos equívocos: "Nesse momento, surge outro condicionante importante à implementação dos direitos sociais, a chamada reserva do possível, ou seja, a implementação dos direitos dependerá do nível de desenvolvimento econômico e social, científico e cultural de cada Estado. Por essa razão diz-se que os direitos sociais são de satisfação progressiva. Porém, a reserva do possível não significa que os direitos sociais somente serão implementados de acordo com os recursos ditos disponíveis pelos administradores; verificar-se-á a aplicação dos mínimos exigidos pela Constituição,bem como a impossibilidade de retrocesso social." PANSIERI, Flávio. Condicionantes à sindicabilidade dos direitos sociais. In: LIMA, Martonio Mont'Alverne Barreto; ALBUQUERQUE, Paulo Antonio Menezes, (Orgs.), op. cit., v. 1, p. 270. 
liberdades e obrigações. Às liberdades ${ }^{(16)}$ normalmente estão vinculados os cidadãos em geral, enquanto que às obrigações ${ }^{(17)}$, está o Estado, parte vinculado. Além disso, desde a adoção do Pacto, uma gama de novas variáveis fez com que fosse necessário considerar um espectro mais abrangente para a interpretação do art. 12, pois outros obstáculos foram opostos à realização do direito à saúde ${ }^{(18)}$.

Segundo a interpretação dada pelo Comitê da ONU ao art. 12.1, o direito à saúde não se restringe ao atendimento e cuidado médicos disponíveis, mas, será implementado também por outras medidas, tais como: acesso à água limpa e potável, adequado saneamento básico, condições ambientais e de trabalho sadias, bem como a participação popular nos processos de decisão, em distintos níveis.

O Comitê da ONU ressalta que a implementação do direito à saúde depende de uma diversidade de condições adotadas pelo Estado-Parte, tais como: (a) Disponibilidade de serviços, materiais e programas (Availability); (b) Acessibilidade (Acessibility) ao que estiver disponível, sendo que esta última depende de 4 componentes: não-discriminação, condições físicas, econômicas e informativas de acesso à saúde (Physical acessibility, Economic acessibility and Information acessibility); (c) aceitabilidade (Acceptability) das instalações e serviços; (d) qualidade (quality) das instalações e serviços.

Quanto às obrigações estatais, os comentários da ONU as classificam em duas espécies: obrigações gerais e obrigações primordiais (core obligations). Quanto às obrigações gerais, assim como os demais direitos humanos, o direito à saúde ensejaria: obrigação de respeitar ${ }^{(19)}$, proteger $^{(20)}$ e fomentar ${ }^{(21)}$.

(16) "As liberdades incluem o direito de controle da saúde e da integridade física, inclusive quanto à liberdade sexual e reprodutiva, além do direito de se ver livre de intervenções, bem como de torturas, experimentos e tratamentos médicos não consensuais." [tradução livre] U. N. CESCR, General Comment 14, U. N. Doc. E/C. 12/200/4 (2000), cit.

(17) "Em contraposição, as definições incluem o direito a um sistema de proteção de saúde que provê igualdade de oportunidades às pessoas de usufruir o melhor nível disponível de saúde." [tradução livre] U. N. CESCR, General Comment 14, U. N. Doc. E/C. 12/200/4 (2000), cit.

(18) "Uma definição mais abrangente de saúde leva em conta também questões sociais relacionadas, tais como violência e conflitos armandos. Além disso, doenças formalmente desconhecidas, tais com oHIV/AIDS, e outras mais abrangentes, como câncer, bem como alto crescimento populacional, criam novos obstàculos à realização do direito á saúde, que devem ser considerados na interpretação do art. 12 [tradução livre]." U.N. CESCR, General Comment 14, U. N. Doc. E/C. 12/200/4 (2000), cit.

(19) Segundo o item 34 dos comentários gerais da ONU, tais obrigações se referem à concessão de igual acesso a todas as pessoas, inclusive presos, minorias, imigrantes, sem discriminação, bem como controlar a segurança do fornecimento de drogas seguras, por exemplo. U. N. CESCR, General Comment 14, U. N. Doc. E/C. 12/200/4 (2000), cit.

(20) Segundo o item 35 dos comentários gerais da ONU, tais obrigações se referem à adoção de medidas legislativas e administrativas que garantam igual acesso a tratamento de saúde e serviços relacionados, por exemplo. U. N. CESCR, General Comment 14, U. N. Doc. E/C. 12/200/4 (2000), cit. (21) Segundo os itens 36 e 37 dos comentários gerais da ONU, tais obrigações se referem à adoção de medidas legislativas e políticas públicas capazes de efetivamente realizar o direito à saúde, nos mais diversos níveis (programas de imunização, fornecimento de saneamento básico e água limpa e potável etc.). U. N. CESCR, General Comment 14, U. N. Doc. E/C. 12/200/4 (2000), cit. 
Quanto às obrigações estatais em nível internacional, o Comitê da ONU informa ${ }^{(22)}$ que os Estados-Partes devem tomar medidas progressivas de cooperação e assistência mútuas, para o pleno implemento dos direitos previstos no Pacto ${ }^{(23)}$. Quanto ao direito à saúde, os Estados devem respeitar o desfrute de serviços de saúde em outros países e facilitar o acesso a sistemas e instalações de saúde em outros Estados, por exemplo.

Quanto às obrigações primordiais (core obligations), o Comitê da ONU ressalta que o direito à saúde deve ser implementado pelos Estados-Partes com, pelo menos, um mínimo de condições de serviços, instalações e programas de saúde ${ }^{(24)}$.

As violações ao direito à saúde, conforme o Pacto, são respectivas às obrigações, ou seja, violações de respeitar, de proteger e de fomentar. Os comentários gerais informam, quanto à implementação em nível nacional do direito à saúde, que as medidas eficazes para tal mister variam conforme as circunstâncias específicas. Contudo, um mínimo de direcionamentos é possível, a partir da obrigação de prestação de um mínimo essencial e da necessidade de aumento progressivo no nível de implementação, bem como na formulação de indicadores e estatísticas, enquanto forma de monitoramento da referida implementação. Além disso, os comentários gerais da ONU informam a necessidade de existirem efetivos mecanismos judiciais para as vítimas, em níveis nacional e internacional, para prevenir e combater a violação ao direito à saúde.

Um último aspecto importante a ser considerado no estudo do art. 12, de acordo com os comentários gerais da ONU, diz respeito ao papel proeminente de atores não-estatais e às obrigações que podem a eles ser impostas, tais como a ONU, a Organização Mundial da Saúde, a UNICEF e organizações não-governamentais várias. Eles são incentivados a auxiliar os Estados na coordenação de programas, estratégias e provisão direta de assistência àqueles que necessitam da implementação do direito à saúde.

\section{SOBRE A JUSTICIABILIDADE DO DIREITO À SAÚDE A PARTIR DE SUA A DIMENSÃO DE PROTEÇÃO AMBIENTAL CONTIDA NO ART. 12.2(B) DO PACTO}

Em termos didáticos, há doutrinadores que classificam os direitos em gerações $^{(25)}$ ou dimensões ${ }^{(26)}$. Muitas críticas existem em relação à classifica-

(22) Conforme prevêem os comentários gerais de n. 03 .

(23) Segundo o item 38 do U. N. CESCR, General Comment 14, U. N. Doc. E/C. 12/200/4 (2000), cit.

(24) Por exemplo, para grupos marginalizados, evitar a desnutrição, promover um mínimo de saneamento, acesso a drogas essenciais, atendimento eqüitativo, elaboração de estratégias e planos de ação, bem como outras obrigações de igual prioridade comparativa, tais como: assistência pré e pósnatal, programas de imunização, prevenção e educação, fornecimento de informação etc. U. N. CESCR, General Comment 14, U.N. CESCR, General Comment 14, U. N. Doc. E/C. 12/200/4 (2000), cit. (25) Nesse sentido, consultar, por exemplo: BOBBIO, Norberto. A era dos direitos. Rio de Janeiro: Campus, 2004.

(26) Nesse sentido, consultar, por exemplo: SARLET, Ingo Wolfgang. A eficácia dos direitos fundamentais. 5. ed. rev. atual. e ampl. Porto Alegre: Livraria do Advogado, 2005. p. 53 e ss. 
ção de gerações, pelo fato de normalmente confundirem o desenvolvimento dos direitos como uma gradativa evolução, pautada por uma linearidade em que a mais nova substitui a anterior. Da mesma forma, também a adoção do conceito de dimensão, de que fala Ingo Sarlet, ao realçar distintas dimensões dos direitos, sem sobreposição de gerações, pode acabar levando a um mesmo efeito. O referido autor considera os direitos econômicos, sociais e culturais como direitos de segunda dimensão, pois "a nota distintiva destes direitos é a sua dimensão positiva, uma vez que se cuida não mais de evitar a intervenção do Estado na esfera da liberdade individual, mas, sim, (...), de propiciar um direito de participar do bem-estar social"(27). Em sentido semelhante, Celso Lafer destaca que os direitos econômicos, sociais e culturais, "pelas suas características de "objetivos" a serem realizados progressivamente por uma coletividade, através da ação estatal, são menos suscetíveis de aplicação imediata"(28).

Portanto, de modo geral, a doutrina adota a idéia de que os direitos econômicos, sociais e culturais não possuem aplicabilidade imediata e são considerados de segunda dimensão ou geração(29). Diante deste ponto inicial, passa-se a investigar a justiciabilidade do direito à saúde, enquanto direito sociall(30) constante do Pacto.

Em primeiro lugar, o termo justiciabilidade usado aqui (justiciability) diz respeito à idéia de aplicabilidade dos direitos, ou seja, à possibilidade de fazer valer (não necessariamente, mas até judicialmente) os direitos econômicos, sociais e culturais, quando não previamente garantidos pelo Estado( ${ }^{(31)}$. $O$ problema, em nível internacional, segundo Martin Scheinin, refere-se a dois pontos específicos: a forma como as prescrições normativas foram formuladas e a relativamente fraca efetividade de mecanismos internacionais de monitoramento frente a ameaças a estes direitos ${ }^{(32)}$.

(27) SARLET, Ingo Wolfgang. op. cit., p. 55.

(28) LAFER, Celso. A reconstrução dos direitos humanos: um diálogo com o pensamento de Hanna Arendt. São Paulo: Companhia das Letras, 1998. p. 129

(29) Em sentido crítico e contrário a essa visão tradicional, destaca Flávio Pansieri: "As disposições constitucionais que tratam dos direitos sociais não são meros instrumentos de referência ou normas programáticas, sem aplicabilidade imediata, conclusão que se extrai pronta da leitura do art. $5^{\circ}$, $\S 1^{\circ}$, da CF/88 (...) Isso não significa dizer que todas as normas definidoras de direitos sociais constituem em direitos subjetivos, no sentido da possibilidade de implementação judicial dos direitos, mas, sim, que essas normas definidoras de direitos e garantias fundamentais possuem eficácia positiva e negativa, tomando em alguns momentos feição de direitos subjetivos." PANSIERI, Flávio, op. cit., p. 268.

(30) "Integram o rol dos Direitos Sociais os direitos que têm por objeto a prevenção e assistência médica geral (direito à saúde), os que garantem uma ajuda financeira na velhice (...)." KRELL, Andreas J. Direitos sociais (verbete). In: BARRETO, Vicente de Paulo (Coord.). Dicionário de filosofia do direito. Rio Grande do Sul: Unisinos; Rio de Janeiro: Renovar, 2006. p. 258.

(31) The problem relating to the legal nature of social and economic right does not relate to their validity but rather to their applicability. Many authors are of the opinion that economic and social rights, because of their very nature, are not justiciable in the sense that they are not capable of being invoked in courts of law and applied by judges. (...) Others make a distinction betwen obligations of result and obligations of conduct and classify economic and social rights under the latter category. SCHEININ, Martin, op. cit., p. 29-30.

(32) Id. Ibid., p. 30. 
O Pacto Internacional sobre direitos econômicos, sociais e culturais, após dez anos de sua finalização enquanto disposição normativa, não havia ainda entrado em vigor por falta do número mínimo de ratificações, o que, de certa forma, já ilustra a dificuldade de sua implementação ${ }^{(33)}$. Ainda segundo Martin Scheinin, no plano internacional, os direitos presentes no Pacto acabam sendo desenvolvidos numa utilização (argumentação) integrada aos procedimentos e ameaças relacionados aos direitos políticos e civis ${ }^{(34)}$.

Quanto à questão da justiciabilidade dos direitos econômicos, sociais e culturais, vale ressaltar que muitos autores enxergam tais direitos como obrigações de conduta, mais envolvidos com a formulação de políticas públicas do que com o caráter de exigibilidade de um direito subjetivo(35).

A análise da justiciabilidade destes direitos direciona-se para o plano interno dos Estados-Partes. Nesse caso, a possibilidade de aplicação com maior ênfase dos direitos econômicos, sociais e culturais vai depender muito, como já visto, de todo um conjunto de circunstâncias sócio-econômicas favoráveis à implementação do direito à saúde ${ }^{(36)}$.

Diante das múltiplas possibilidades de análise, restringe-se aqui o enfoque da análise da justiciabilidade do direito à saúde, em relação a sua dimensão de proteção ambiental, ou seja, como pode se dar a justiciabilidade do direito à saúde relacionado a sua dimensão ambiental (ou direito ao meio ambiente sadio), no plano interno.

Uma primeira questão necessária é a ponderação sobre a dimensão ambiental do direito à saúde permitir a defesa/configuração (pelo art. 12.2 (b) do Pacto) do meio ambiente (direito ao ambiente sadio) como um direito humano fundamental|(37). Parece complicado e tortuoso querer evidenciar a

(33) SCHEININ, Martin. op. cit., p. 31.

(34) Id. Ibid., p. 32.

(35) "Economic and social rights are generally concerned with encouraging governments to pursue policies which create conditions of life enabling individuals, or in some case groups, to develop equally to their full potencial. They are seen as programmatic, requiring progressive realization in accordance with available resources. Implementation of these rights is normally monitored only by relatively weak reporting systems." BIRNIE, Patricia N; BOYLE, Alan. E. Internacional law and the environment. 2. ed. Oxford University Press: 2002. p. 253.

(36) Para estudo da realidade brasileira, recomenda-se o trabalho de Flávia Piovesan, que direciona sua análise a casos relacionados ao direito à educação e à saúde (relativos ao fornecimento de medicamentos e ao acesso à assistência médico-hospitalar; relativos a tratamentos diferenciados, relativos à responsabilidade por dano à saúde e ao alcance dos contratos de seguros de saúde) no Supremo Tribunal Federal e no Superior Tribunal de Justiça brasileiros, ressaltando que "considerando o alcance da proteção constitucional dos direitos sociais e econômicos, importa avaliar o grau de justiciabilidade destes direitos nas Cortes brasileiras." PIOVESAN, Flávia, op. cit., p. 255-264. (37) Apenas para revelar a pertinência da discussão, vale ressaltar que o Supremo Tribunal Federal já se pronunciou acerca da existência de um direito humano fundamental ao meio ambiente sadio e equilibrado. Nas palavras do relator da ação (Ministro Celso de Mello): Em suas palavras, "Trata-se, consoante já o proclamou o Supremo Tribunal Federal (RTJ 158/205-206, Rel. Min. CELSO DE MELLO), de um típico direito de terceira geração (ou de novíssima dimensão), que assiste, de modo 
proteção ao meio ambiente sadio como um direito humano, a partir do Pacto, diante das peculiares características deste último, relacionado com características intrínsecas ao homem (vida, liberdade, saúde). Assim entendem Boyle e Birne ${ }^{(38)}$, ao asseverar que não se encaixa o direito ao ambiente sadio como um direito humano(39).

Contudo, não se trata de perspectiva indefensável. Há relatos de casos judiciais, na América Latina, conforme destaca o Relatório $6^{(40)}$ do Joint UNEP-OHCHR Expert Seminar on Human Rights and the Environment (14-16 January 2002/ Geneva), que estão elevando o direito ao ambiente sadio como direito humano fundamental, com indicação de métodos e técnicas próprias à densificação e fundamentação de tal direito.

Tendo o direito à saúde certamente uma dimensão ambiental (art. 12.2 (b)), surgem algumas opções. Pelo Pacto, é possível (a) defender a proteção ambiental por este artigo ou, ainda, é possível (b) a defesa do direito à saúde, que se concretiza também por meio da proteção ambiental, enquanto aporte ou condição de implementação do direito à saúde.

Ao se pensar em defender o meio ambiente isolado do direito à saúde pelo art. 12.2 (b), percebe-se que o caminho é muito estreito, tortuoso e

subjetivamente indeterminado, a todo o gênero humano, circunstância essa que justifica a especial obrigação - que incumbe ao Estado e à própria coletividade — de defendê-lo e de preservá-lo em benefício das presentes e futuras gerações, evitando-se, desse modo, que irrompam, no seio da comunhão social, os graves conflitos intergeneracionais marcados pelo desrespeito ao dever de solidariedade na proteção da integridade desse bem essencial de uso comum de todos quantos compõem o grupo social." E consta o seguinte na ementa desse aresto: "A preservação da integridade do meio ambiente: expressão constitucional de um direito fundamental que assiste à generalidade das pessoas." BRASIL. Supremo Tribunal Federal. Medida Cautelar em Ação Direta de Inconstitucionalidade 3.540-1 - Distrito Federal (ADI n. 3.540 - MC/DF) Tribunal Pleno. Relator: Ministro Celso de Melo, julgado: 01.09.2005, DJU: 3.2.2006, PP-00014 EMENT. VOL.-02219-03, PP-00528. Disponível em: <http://www.stf.gov.br/jurisprudencia/IT/frame.asp?PROCESSO=3540\&CLASSE= ADI\%2DMC\&cod_classe=555\&ORIGEM=IT\&RECURSO=0\&TIP_JULGAMENTO=M\&EMENTA=2219>. Acesso em: 24 ago. 2005.

(38) A esse respeito, eles ressaltam o seguinte entendimento de Dupuy: "Dupuy argues that the right to a decent environment is not inherent in the human condition, unlike the right to life, that is character is derived from other economic and social rights, like the right to health, and that it lacks any mechanism for enforcement." BIRNIE, Patricia N; BOYLE, Alan. E., op. cit., p. 256.

(39) "It is important to stress that environmental rights do not fit nearly into any single category of generation of human rights; rather, they straddle all three of the above categories. First, drawing on existing civil and political rights. A second possibility is to treat a decent, healthy or viable environment as an economic or social right, comparable to those already protected in the 1966 ESCR Covenant... The third option of treating environmental quality as a solidarity right ..." Id. Ibid., p. 253. (40) "From a survey of these court cases three important lessons can be drawn: first, the courts are moving the right to a healthy environment up the hierarchy of human rights by recognising it as a fundamental right; second, the courts are defining the content and nature of the right to a healthy environment through landmark decisions; and third, the cases indicate which methods are most effective to protect these rights." BACKGROUND 6 - Joint UNEP-OHCHR Expert Seminar on Human Rights and the Environment (14-16 January 2002, Geneva). Disponível em: <http://www.unhchr.ch/ environment/bp6.html>. Acesso em: 14.01.07. 
inócuo. Isto porque diversos são os tratados de direito internacional, que sem abordar necessariamente os direitos humanos, servem muito bem à defesa da sustentabilidade ambiental. Valer-se deste Pacto Internacional para tanto parece algo pouco eficaz juridicamente.

Portanto, parece mais sensato e coerente com os objetivos e as características do Pacto Internacional, valer-se da perspectiva que considera que os problemas de definição e justiciabilidade do direito à saúde podem ter soluções com melhores ganhos objetivos, conforme Boyle e Birne ${ }^{(41)}$, quando relacionado tal direito com a melhoria da condição ambiental, na medida em que a melhoria desta é um fator socioeconômico que fortalece o direito à saúde.

Talvez seja uma boa opção para incrementar a justiciabilidade do direito à saúde, com base no art. 12.2 (b), a que considera a dimensão de proteção ambiental como um fator que implementa com maior ênfase a concretização do direito à saúde.

Assim, se manifestam algumas conclusões do relatório Joint UNEPOHCHR Expert Seminar on Human Rights and the Environment (14-16 January 2002/ Geneva), ao ressaltar a necessidade de maior integração dos direitos humanos (inclusive direitos econômicos, sociais e culturais) aos direitos do meio ambiente (proteção ambiental) ${ }^{(42)}$.

(41) "Up to a point, problems of definition can be overcome by adopting a more specific focus, for example on health, rather than on the vaguer and more subjetive criteria of decency, satisfaction, or viability. Article 12 of the 1966 Economic and Social Covenant illustrates this approach, but its reference to "the improvement of all aspects of environmental and hygiene" is so narrow that is scarcely addresses environmental protection at all." BIRNIE, Patricia W; BOYLE, Alan. E., op. cit., p, 257.

(42) "The experts recognized that normative links between the fields of human rights and the environment need to be reinforced, beyond existing guarantees provided in national and international instruments and practices. Specifically, and in the context of the forthcoming World Summit on Sustainable Development: To enhance public awareness, especially in the corporate sector, of the connections between human rights protection and environmental protection; and With regard to substantive rights, further steps need to be taken: a) To affirm the link between human rights and environmental protection as an essential tool in the eradication of poverty and the achievement of sustainable development; b) To treat economic, environmental and human rights norms in an integrated manner, and develop legal and other concepts and techniques for achieving such integration; c) To recognize the environmental dimension in the effective enjoyment of human rights protection and promotion, and the human rights dimension in environmental protection and promotion, in part by developing rights-based approaches to environmental protection and promotion of sustainable development; With regard to institutional arrangements, the linkage between human rights and the environment is in need of reinforcement. This could be achieved by: Ensuring that environmental bodies and procedures are fully aware of the increasing environmental role played by human rights bodies and procedures, and that human rights bodies are fully aware of the increasing human rights role played by environmental institutions and procedures;" [com adaptações] FINAL Text (16 January 2002). In: MEETING OF EXPERTS ON HUMAN RIGHTS AND THE ENVIRONMENT. 14-15 JANUARY 2002. Conclusions. Disponível em: <http://www.unhchr.ch/environment/conclusions.html>. Acesso em: 14 jan. 2007. 


\section{JUSTICIABILIDADE DO DIREITO À SAÚDE A PARTIR DO PACTO INTERNACIONAL: DESAFIOS E PERSPECTIVAS}

Pode-se afirmar que existe margem de justiciabilidade do direito à saúde a partir do Pacto Internacional, em relação ao ordenamento jurídico brasileiro, seja em sentido formal - o que é mais simples (porque incorporado formalmente ao ordenamento nacional), seja em sentido material (porque passível de ser efetivamente aplicado). O nível de implementação das obrigações e cumprimento dos deveres pelos Estados-Partes e por outros atores não estatais vincula-se as suas características e peculiaridades socioeconômicas, as quais, contudo, não devem servir de fundamento para uma inércia, sob pena de violação tanto do Pacto Internacional, como do ordenamento jurídico de cada país, a exemplo do Estado brasileiro, que alberga a proteção à saúde em nível constitucional, enquanto direito humano fundamental, a exigir parâmetros mínimos de observância ${ }^{(43)}$.

A dificuldade de um alto nível de justiciabilidade do direito à saúde passa, inclusive, pelo enfrentamento de outros desafios internos, quais sejam, a sua implementação em sentido material, visto que, segundo Flávia Piovesan, em estudo de casos judiciais brasileiros, há um déficit na aplicação/observância dos padrões mínimos de exigência previstos no Pacto Internacional, tanto por parte dos órgãos julgadores, quanto pela ausência de suscitação, nesse sentido, pelos litigantes ${ }^{(44)}$.

Assim, deve haver maior esclarecimento e estímulo à necessidade de tornar mais efetivas e eficazes ${ }^{(45)}$ as prescrições do Pacto Internacional, sobretudo o art. 12.2 (relativo ao direito à saúde) e artigos introdutórios e gerais que orientam sua aplicação (complementados pelos comentários gerais da

(43) "Nesse núcleo sindicável na dimensão positiva factível temos, ainda, a saúde básica. Nesse caso, utiliza-se como parâmetro os planos básicos de saúde privada, e ainda o princípio da universalização do atendimento igualitário como tutela do bem maior do Estado, que é a vida. Observar-se-á ainda a garantia de uma aplicação mínima dos recursos do Estado em saúde, que em caso de desrespeito será motivo de intervenção ou mesmo como se tem visto nos tribunais com as ações civis com obrigação de fazer, para a implementação do atendimento." PANSIERI, Flávio, op. cit., p. 272.

(44) "As decisões judiciais estudadas, seja na área da saúde ou da educação, não mencionam os tratados internacionais de proteção de direitos humanos, nem tampouco as observações gerais da ONU. O silêncio quanto à incorporação dos parâmetros protetivos mínimos da ordem internacional revela tanto o desconhecimento do Poder Judiciário a respeito da matéria e sua vocação refratária ao Direito Internacional, como também a não-utilização de tais instrumentos internacionais de direitos humanos pelos próprios litigantes. $\mathrm{O}$ incipiente grau de provocação do Poder Judiciário para demandas envolvendo a tutela dos direitos sociais e econômicos, revela a apropriação ainda tímida pela sociedade civil dos direitos econômicos, sociais e culturais como verdadeiros direitos legais, acionáveis e justiciáveis." PIOVESAN, Flávia, op. cit., p. 262-263.

(45) "Assim, enquanto a efetividade estaria relacionada ao estudo dos efeitos sociais produzidos pelas normas jurídicas; a eficácia estaria jungida ao exame de seus efeitos jurídicos." BEDÊ, Fayga Silveira, op. cit., p. 227. 
ONU), em conjunto com as prescrições constitucionais e infraconstitucionais brasileiras, pois, trata-se de norma de caráter cogente e direcionadora da atuação estatal e da sociedade civil, em todos os seus níveis, enquanto medida ampliativa do nível de justiciabilidade ${ }^{(46)}$ do direito à saúde.

Outra medida ampliativa do nível de justiciabilidade do direito à saúde é a implementação da dimensão de proteção ambiental do direito à saúde, pois, potencializa a sua fruição, vinculada a outros deveres e obrigações postos ao Estado e à sociedade civil.

A divergência doutrinária existente quanto à consideração da dimensão de proteção ambiental como co-fator, pré-condição ou direito concorrente ao direito à saúde (art. 12.2 (b)) não parece ter grande relevância. A perspectiva que parece ser mais consentânea aos objetivos do Pacto e às características históricas de sua criação e desenvolvimento aponta para a idéia de que a tal dimensão enquadra-se como um co-fator que potencializa o direito à saúde, auxiliando, inclusive, na ampliação de seu grau de justiciabilidade.

Esta opção doutrinária, que enquadra tal dimensão como uma précondição(47) à concretização do direito à saúde, pode, por um lado, permitir uma melhor conformação da aplicação do art. 12.2 (b) ${ }^{(48)}$, a viabilizar melhores ganhos objetivos na justiciabilidade do direito à saúde. Contudo, pode parecer excessivamente estreita no que tange à necessidade de maior proteção ambiental por meio do art. 12.2 (b). Mas, não parece ser essa a finalidade precípua do art. 12.2 (b). Sobre tal limitação, Dinah Shelton e Adriano Trindade $^{(49)}$ apontam que isto ocorreu também porque a maioria dos tratados

(46) Segundo Flávia Piovesan: "Ainda que incipiente, a justiciabilidade dos direitos sociais e econômicos na experiência brasileira é capaz de invocar um legado transformador e emancipatório, com a ruptura gradativa de uma visão conservadora e formalista do Poder Judiciário. Assinala-se, como caso emblemático, as decisões judiciais acerca do fornecimento gratuito de medicamentos, que, somadas a articuladas e competentes estratégias de litigância, fomentaram transformações legislativas e a adoção de políticas públicas consideradas exemplares na área." PIOVESAN, Flávia, op. cit., p. 264. (47) Entende-se, a despeito do jogo de palavras, que a idéia de co-fator seja mais adequada, no sentido de não se ter que atingir primeiramente um grau elevado de qualidade ambiental para, só então, iniciar-se a possibilidade de fruição do direito à saúde. Assim, portanto, deve ser entendido o termo pré-condição.

(48) Nesse sentido, ressalta Dinah Shelton: "The first approach, perhaps closest to that of the Stockholm Declaration, understands environmental protection as a pre-condition to the enjoyment of internationalityguaranteed human rights, especially the right to life and health." SHELTON, Dinah. Human rights, health and environmental protection: linkages in law and practice. In: LEÃO, Renato Zerbini Ribeiro (Coord.). Os rumos do direito internacional dos direitos humanos: ensaios em homenagem ao professor Antônio Augusto Cançado Trindade. Porto Alegre: Sérgio Antônio Fabris, 2005. p. 394.

(49) "Concern about environmental issues has been growing for the past few decades and nowadays is subject of several international instruments, but it has not always been as such. The right to a healthy environment is a concept which developed more recently and, perhaps thereby, the Universal Declaration of Human Rights and the two 1966 International Covenants do not provide specifically for such a right, even though it may be admitted that these instruments present a framework for environmental protection." TRINDADE, Adriano Drummond Cançado. The international protection of human rights and natural resources development: the role of International Courts of Human Rights. In: LEÃO, Renato Zerbini Ribeiro (Coord.), op. cit., p. 436. 
de direitos humanos foi elaborada e adotada antes da proteção ambiental tornar-se claramente um assunto de direito internacional ${ }^{(50)}$.

Contudo, atualmente tal realidade não mais se sustenta, pois a emergência da questão ambiental e sua relação com os mais diversos campos do conhecimento(51), aliada aos efeitos da globalização, que nos direciona a novas escalas de observação dos fatos ${ }^{(52)}$, implicou na criação de amplo arcabouço normativo de direito ambiental internacional, com forte presença da questão ambiental no debate jurídico-político mundial.

Constata-se ainda que a proteção ambiental exerce essencial dimensão propulsora do direito à saúde, inclusive na implementação de sua justiciabilidade, em relação às prescrições normativas do Pacto Internacional. Resta saber, agora, não só quais os rumos da proteção ambiental e do atual direito ao ambiente, juntamente com o direito à saúde, visto que o desenvolvimento do direito ao ambiente sadio e equilibrado tem suscitado novas classificações e aproximações com os direitos humanos, mas, também de que forma se relacionará com o direito à saúde: como pré-condição, como condição concomitante ou como um direito a ser implementado em conjunto com o direito à saúde? Mas, para além do intento meramente conceitual e classificatório, que efeitos práticos e objetivamente vantajosos tais novas considerações trarão tanto ao desenvolvimento do bem-estar social, individual e coletivamente considerado (mundial), assim como da própria potencialidade do direito à saúde e, por que não, talvez mesmo, ao desenvolvimento de um direito humano fundamental ao ambiente sadio, fortalecendo e incrementando a ainda pequena proteção (embora relevante) já existente no Pacto Internacional? Certo é que a relação entre meio ambiente e direitos humanos, sobretudo com o direito à saúde, ainda promete muitas interações ${ }^{(53)}$.

(50) TRINDADE, Adriano Drummond Cançado, op. cit., p. 396. p. 396.

(51) No contexto de uma crescente análise político-internacional dessa nova conscientização, destaca-se o seguinte: "De maneira simplificada, a evolução da política ambientalista internacional pode se decompor em três fases distintas, cada uma desenvolvendo características que se encontrarão nas fases seguintes. Inicialmente houve várias ações variadas, às vezes intensas, porém limitadas, indo do fim do século XIX à Conferência da Unesco de 1968. Em seguida, a irrupção das questões ambientais na cena internacional, ao final dos anos 1960, deu origem a um período de ativismo intenso, após o qual veio certo cansaço em um contexto internacional difícil (1968-1986). Por fim, assiste-se a uma ressurgência e uma nova presença das questões ambientais, caracterizadas pela multiplicação, aceleração e complexificação progressivas das interações internacionais e das questões tratadas desde 1987." LE PRESTRE, Philippe. Ecopolítica internacional. Tradução de Jacob Gorender. São Paulo: Senac, 2000. p. 159-160.

(52) "No século XX, as tentativas da Liga das Nações e os esforços da Organização das Nações Unidas pretenderam uma consideração mundial dos problemas e, mais recentemente, as questões ambientais obrigaram uma focalização que toma como unidade de referência o planeta e a espécie humana, também vistos como um todo." [grifo nosso] ZAJDSZNAJDER, Luciano. Ética, estratégia e comunicação na passagem da modernidade à pós-modernidade. 2. ed. Rio de Janeiro: Ed. FGV, 1999. p. 37.

(53) "Se a interdependência dos direitos humanos e do meio ambiente é, atualmente, inquestionável, dado o reconhecimento do direito fundamental ao meio ambiente e ao direito ao desenvolvimento, 


\section{REFERÊNCIAS BIBLIOGRÁFICAS}

ANNONI, Danielle. Direitos humanos e meio ambiente: contribuições para a humanização do direito internacional contemporâneo. In: LEÃO, Renato Zerbini Ribeiro (Coord.). Os rumos do direito internacional dos direitos humanos: ensaios em homenagem ao professor Antônio Augusto Cançado Trindade. Porto Alegre: Sérgio Antônio Fabris, 2005.

BACKGROUND 6-Joint UNEP-OHCHR Expert Seminar on Human Rights and the Environment (14-16 January 2002, Geneva). Disponível em: <http:// www.unhchr.ch/environment/bp6.html>. Acesso em: 14 jan. 2007.

BEDÊ, Fayga Silveira. A erosão normativa da Constituição e os seus reflexos sobre a justicialização dos direitos fundamentais sociais. In: LIMA, Martonio Mont'Alverne Barreto; ALBUQUERQUE, Paulo Antonio Menezes (Orgs.). Democracia, direito e política: estudos internacionais em homenagem a Friedrich Müller. 1. ed. Florianópolis: Conceito Editorial; Fundação Boiteux, 2006, v. 1 , p. 225-235.

BIRNIE, Patricia W; BOYLE, Alan. E. Internacional law and the environment. 2. ed. Oxford University Press: 2002.

BOBBIO, Norberto. A era dos direitos. Rio de Janeiro: Campus, 2004.

BRASIL. Constituição (1998). Constituição da República Federativa do Brasil. Disponível em: <http://www.planalto.gov.br/ccivil_03/Constituicao/ Constituiçao.htm>. Acesso em: 25 jul. 2007.

DECRETO Presidencial n. 591, de 6.7.92. Disponível em: <http:// www.planalto.gov.br/ccivil_03/decreto/1990-1994/D0591.htm>. Acesso em: 25 jul. 2007.

FINAL Text (16 January 2002). In: MEETING OF EXPERTS ON HUMAN RIGHTS AND THE ENVIRONMENT. 14-15 JANUARY 2002. Conclusions. Disponível em: <http://www.unhchr.ch/environment/conclusions.html>. Acesso em: 14 jan. 2007.

KRELL, Andreas J. Direitos sociais (verbete). In: BARRETO, Vicente de Paulo (Coord.). Dicionário de filosofia do direito. Rio Grande do Sul: Unisinos; Rio de Janeiro: Renovar, 2006.

LAFER, Celso. A reconstrução dos direitos humanos: um diálogo com o pensamento de Hanna Arendt. São Paulo: Companhia das Letras, 1998.

\footnotetext{
como imprescindíveis à manutenção da vida no (e do) planeta, a convergência dos mecanismos internacionais de proteção destes dois sistemas ainda apresenta carências profundas no plano de sua efetivação." ANNONI, Danielle. Direitos humanos e meio ambiente: contribuições para a humanização do direito internacional contemporâneo. In: LEÃO, Renato Zerbini Ribeiro (Coord.), op. cit., p. 514.
} 
LE PRESTRE, Philippe. Ecopolítica internacional. Tradução de Jacob Gorender. São Paulo: Senac, 2000.

PANSIERI, Flávio. Condicionantes à sindicabilidade dos direitos sociais. In: LIMA, Martonio Mont'Alverne Barreto; ALBUQUERQUE, Paulo Antonio Menezes (Orgs.). Democracia, direito e política: estudos internacionais em homenagem a Friedrich Müller. 1. ed. Florianópolis: Conceito Editorial; Fundação Boiteux, 2006, v. 1, p. 265-273.

PICOLOTTI; Romina; BORDENAVE; Sofía. A new development strategy for the americas: a human rights and the environment perspective. Disponível em: <http://www.cedha.org.ar/docs/doc79-eng.htm>. Acesso em: 14 jan. 2006.

PIOVESAN, Flávia. Justiciabilidade dos direitos sociais e econômicos no Brasil: desafios e perspectivas. In: LIMA, Martonio Mont'Alverne Barreto; ALBUQUERQUE, Paulo Antonio Menezes (Orgs.). Democracia, direito e política: estudos internacionais em homenagem a Friedrich Müller. 1. ed. Florianópolis: Conceito Editorial; Fundação Boiteux, 2006, v. 1, p. 251-264.

SARLET, Ingo Wolfgang. A eficácia dos direitos fundamentais. 5. ed. rev. atual. e ampl. Porto Alegre: Livraria do Advogado, 2005.

SCHEININ, Martin. Economic and social rights as legal rights. In: ASBJOM, Eide; KRAUSE, Catarina; ALLAN, Rosas (Eds.). Economic, social and cultural rights: a textbook. 2nd ed. Dordrecht: Martinus Nijhoff Publishers, 2001.

SHELTON, Dinah. Human rights, health and environmental protection: linkages in law and practice. In: LEÃO, Renato Zerbini Ribeiro (Coord.). Os rumos do direito internacional dos direitos humanos: ensaios em homenagem ao professor Antônio Augusto Cançado Trindade. Porto Alegre: Sérgio Antônio Fabris, 2005.

SILVA, José Afonso da. Curso de direito constitucional positivo. 23. ed. São Paulo: Malheiros Ed., 2004.

TRINDADE, Adriano Drummond Cançado. The international protection of human rights and natural resources development: the role of International Courts of Human Rights. In: LEÃO, Renato Zerbini Ribeiro (Coord.) Os rumos do direito internacional dos direitos humanos: ensaios em homenagem ao professor Antônio Augusto Cançado Trindade. Porto Alegre: Sérgio Antônio Fabris, 2005.

U. N. CESCR, General Comment 14, U. N. Doc. E/C. 12/200/4 (2000). Disponível em: <http://www.unhchr.ch/tbs/doc.nsf/(symbol)/E.C.12.2000.4.En? OpenDocument>. Acesso em: 14 jan. 2007.

ZAJDSZNAJDER, Luciano. Ética, estratégia e comunicação na passagem da modernidade à pós-modernidade. 2. ed. Rio de Janeiro: Ed. FGV, 1999. 